\title{
NONADA: FILOSOFIA, MEMÓRIA E IDENTIDADE EM DRUMMOND
}

Roberto Said

UFMG

\begin{abstract}
RES U M O
O trabalho examina a "incessante busca identitária" e a "obsessão autobiográfica" na poesia de Carlos Drummond de Andrade.
\end{abstract}

PALAVRAS - CHAVE

Carlos Drummond de Andrade. Poesia brasileira. Memória.

\section{I}

Senti, en la última página, que mi narración era un símbolo del hombre que yo fui, mientras la escribía e que, para redactar esa narración, yo tuve que ser aquel hombre y que para ser aquel hombre, yo tuve que redactar esa narración, y hasta lo infinito.

Jorge Luis Borges

Tomada em seu conjunto, a poesia de Carlos Drummond de Andrade, não obstante a diversidade de seus temas e de sua estética, é atravessada por uma incessante busca identitária, por uma verdadeira obsessão autobiográfica. No curso de sua extensa trajetória artística, que acompanha praticamente todo o século 20 , delineia-se um fio tramado no labirinto da prospecção do ser, modulando a dicção singular de um sujeito em obstinada procura existencial. Todavia, configuram-se aí múltiplas vias ou, melhor dizendo, diferentes dispositivos autobiográficos com os quais o poeta engendra diferentes séries textuais, tecidas sob a mesma compulsão identitária, mas distintas entre si no tocante ao modo, às estratégias e à intensidade com as quais um certo eu se revela e se coloca em cena em cena.

São séries compostas com os signos da memória, ligados à infância, à juventude, ao clã ou à província natal; séries centradas nos signos especulares ou nos signos de duplicação do sujeito do poema, tramados na vizinhança da poética borgeana; séries formadas por signos fantasmáticos; séries de automutilação, quase sempre relacionadas à prática e/ou à condição intelectual; entre outras. Não obstante as diferenças existentes, relevantes sob todos os aspectos, o gesto autobiográfico em Drummond não se realiza em nenhuma dessas séries de modo transparente. Isto porque os referentes que o impulsionam, embora provoquem "efeitos de real" - a expressão é de Barthes - ao imprimirem no poema marcas biográficas reconhecíveis, conferindo-lhe a pretensa legitimidade do verossímil, não se submetem ao princípio de autenticidade factual ou documental da vida. ${ }^{1} \mathrm{O}$ que

${ }^{1}$ BARTHES. Roland Barthes por Roland Barhes. 
está em causa na procura levada a cabo pelo poeta não é a existência de um sujeito empírico. Os pormenores evocados de sua história particular ou de sua trajetória pública, isto é, o "resumo do existido" - para dizer nos termos de sua poesia - feito e desfeito de "cacos, de buracos, / de hiatos e de vácuos, / de elipses e psius," tem pouca valia fora do corpus textual no qual foram anotados. ${ }^{2}$

O empenho do escritor com o elemento autobiográfico, empenho no duplo sentido do termo, - o de dedicação e o de penhora - não visa a atestar nem a reconhecer a verdade do ser, a qual poderia ser supostamente entrevista no curso de um tempo reconstituído. Não obstante a insistência em se perguntar sobre si mesmo, sua obra não se converte em palco um de "reconhecimento recapitulativo", tal como definido por Starobinski. ${ }^{3}$ Também não se pode dizer que institua uma poética da intimidade, à maneira de um diário ou dos diversos gêneros modernos de realismo confessional, através dos quais o sujeito do texto vasculha os mais recônditos espaços da alma, a fim de empreender uma ascese moral ou espiritual. Tampouco se trata de uma tentativa de esquadrinhar ou de unificar estados de consciência através da escrita literária. Nem auto-conhecimento, nem consciência-de-si, nem auto-expiação.

O problema colocado pelo poeta não é o de buscar a forma mais legítima ou a mais verdadeira de expressão ou de representação de si. Nesse sentido, é importante destacar que a genealogia drummondiana inscreve-se no campo das práticas e das formações discursivas modernas, pautado pela crítica da subjetividade e pelo questionamento das categorias relativas ao sujeito e à sua interioridade. Para o poeta formado nas páginas da modernidade literária européia, a concepção do sujeito moderno como um ser cindido e fraturado impunha-se desde a juventude como uma espécie de axioma. Toda a sua poesia, desde o início uma poesia de "homens partidos", revela uma aguda consciência crítica a esse respeito.

Esse movimento paradoxal, essa dupla inscrição - ora de recusa, ora de afirmação do primado de um sujeito-autor - que se deixa imprimir, embora partida, no próprio traço da escrita, só se torna possível porque o elemento autobiográfico, embora esteja disseminado de um canto a outro de sua poesia, não atua senão para colocar em xeque a presença de uma subjetividade ou de uma identidade previamente constituídas:

Perdi minha alma à flor do dia ou já perdera

bem antes sua vaga pedraria?

Mas quando me perdi, se estou perdido

antes de haver nascido

e me nasci votado à perda

de frutos que não tenho nem colhia? ${ }^{4}$

Não há em Drummond um ser dado de antemão, cuja existência se anuncie previamente ao ato de escritura. Como bem observa Mário de Andrade, trata-se de

\footnotetext{
${ }^{2}$ ANDRADE. Poesia e prosa, p. 882: (In) Memória.

${ }^{3}$ STAROBINSKI, apud MIRANDA. Corpos escritos.

${ }^{4}$ ANDRADE. Poesia e prosa, p. 410-412: Elegia.
} 
uma "poesia lançada no caos lírico do ser e não tirada dele". ${ }^{5}$ A ontologia drumondiana não reclama um fundamento originário atestando a presença anterior do ser ou mesmo a sua significação primeira. "Não me procurem que me perdi eu mesmo", avisa o verso de "Elegia", colocando à própria procura sob suspeita, à medida que a instância "responsável" pelo discurso também se confessa perdida. ${ }^{6}$

Nessa máquina de escrita identitária, o dado autobiográfico lançado no poema não desencadeia senão a vertiginosa espiral de desconstrução e duplicação do sujeito auto-biografado. O que prevalece, em quaisquer das formas de evocação de si mesmo, é a desestabilização desse "si" que se deixa ver ou falar na poesia.

Em Drummond, é somente a travessia o que se pode alcançar, somente o ponto de inflexão entre o bio e o graphos, ponto no qual se diluem os limiares e as hierarquias entre aquele que escreve e a sua escrita, o factual e o ficcional, "o jogo e a confissão", "o vivido e o inventado". Pois sendo o espaço de sua literatura pouco refratário, com fronteiras turvas e mal sinalizadas, ele não comporta a rigidez das oposições dentro e fora, interior e exterior, causa e efeito. Sua "significação" não está, portanto, localizada nem na profundidade, nem na exterioridade; nem no tempo, nem no ato da memória, mas nos limiares incessantemente fomentados pelo jogo de auto-ficionalização da escrita: "Tudo vivido? Nada / Nada vivido? Tudo."

É somente nesse espaço intervalar, no qual o texto se confunde com a vida e a vida com o texto, que o sujeito drummondiano se deixa capturar, mas de modo temporário e contingente. É somente nesse movimento instável, no qual permanece e se transforma sob a condição performativa da escrita, que ele pode se entrever, como bem explicava um certo narrador borgiano, citado na epígrafe.

O que se configura em Drummond é, portanto, uma obra delineada sobre o traço de uma subjetividade e, tal como uma dobra, um sujeito produzido como ressonância dessa obra, de seu rastro. Escritor e escrita transitam, portanto, sob o mesmo estatuto ficcional - "essa composição que um dia se chamou Carlos Drummond de Andrade" mas descartam a possibilidade de uma presença identitária, ao se apresentarem em permanente despedida: "Adeus, minha presença, meu olhar e minha veias grossas, / meus sulcos no travesseiro, minha sombra no muro, / sinal meu no rosto, olhos míopes, objetos de uso pessoal idéia de justiça, revolta e sono, adeus, / vida aos outros legadas."

O que a (de)composição drummondiana coloca em curso não é a afirmação positiva da presença de um sujeito ou de um sujeito enquanto presença, mas sim um exercício de "subjetivação" através do qual o poeta pode inventar e reinventar modos de existência singulares. ${ }^{10}$ Esse exercício aponta antes para as intensidades que atravessam o sujeito

\footnotetext{
${ }^{5}$ Carlos 8 Mário, p. 481.

${ }^{6}$ ANDRADE. Poesia e prosa, p. 410-412: Elegia.

${ }^{7}$ ANDRADE. Poesia e prosa, p. 418: Poema-orelha.

${ }^{8}$ ANDRADE. Poesia e prosa, p. 214-217: Os últimos dias.

${ }^{9}$ ANDRADE. Poesia e Prosa, p. 214-217: Os últimos dias.

${ }^{10}$ Segundo Gilles Deleuze (Conversações, p. 188) a subjetivação designa "a operação pela qual indivíduos ou comunidades se constituem como sujeitos, à margem dos saberes e dos poderes estabelecidos”. Não se confunde, portanto, com um sujeito ou com uma identidade, pois "uma subjetividade deve ser produzida, quando chega o momento, justamente porque não há sujeito.”
} 
do que para uma consciência ou identidade já definidas. Sua subjetivação volta-se, portanto, a um ser desalojado, despossuído de si mesmo:

De mim mesmo sou hóspede secreto. ${ }^{11}$

\section{II}

Como pode existir, pensou consigo, um ser que no existir põe tamanha anulação de existência?

Carlos Drummond de Andrade

Moderno por excelência, esse processo de subjetivação levado a cabo na poesia drummondiana revela uma dimensão eminentemente filosófica ou, para dizer com mais precisão, atua à maneira da filosofia. Embora os modos de ideação e construção da obra drummondiana não passem pelos procedimentos formais e teóricos de um tratado filosófico, seu regime discursivo é constantemente arrastado para as bordas do pensamento. Tal como um duplo ou um vizinho da filosofia, sua poesia dá o que pensar, impele o pensamento, criando eixos e orientações pelos quais se desenvolve e se abre ao leitor.

Pode-se mesmo dizer que o lirismo drummondiano deve-se não a um estado de ânimo, mas a um estado de idéias, isto é, de problemas. A maneira de o poeta estar-no-mundo é problemática, conforme profetizara o anjo torto. Seus textos constroem-se, formal e tematicamente, sob a turbulência de um questionamento, de modo a encetar uma espécie de dispositivo analítico. Mesmo os episódios corriqueiros e as cenas comuns da vida cotidiana são alçados em sua poesia à condição de problema, são tomados sob crivo filosófico, como se houvesse sempre um "eu reflexivo por trás do eu." 12

Com efeito, tudo em sua obra parece assumir um acento reflexivo, um ar de meditação; tudo parece subordinar-se ao pensamento, parece convergir para um problema, para uma questão cujo alcance ultrapassa os limites da cena poética e se converte em convite ao pensar:

Meu bem, usemos palavras.

Façamos mundos: idéias. ${ }^{13}$

Pode-se dizer, junto com Deleuze, que em Drummond "o conceito e a criação se remetem uma ao outro" fomentando um ato singular de pensamento. ${ }^{14}$ Ato no qual o mundo e a idéia se confundem, pois para o poeta

\footnotetext{
${ }^{11}$ ANDRADE. Poesia e Prosa, p. 444-451: "A um hotel em demolição".

${ }^{12}$ ARRIGUCCI JR. Coração partido, p. 28.

${ }^{13}$ ANDRADE. Poesia e prosa, p. 258-261: Cantiga de enganar.

${ }^{14}$ DELEUZE. O que é a filosofia?, p. 20. De acordo com o filósofo francês, se há lugar e tempo para a criação dos conceitos, a essa operação de criação sempre se chamará filosofia, ou não se distinguirá da filosofia, mesmo se lhe for dado um outro nome.
} 
O mundo é talvez: e é só.

Talvez nem seja talvez. ${ }^{15}$

Sempre me pareceu que, se há realmente um estilo em Drummond - esse conceito cujo fim duvidoso é identificar e reunir as particularidades autorais de um indivíduo ou grupo - seja considerado sob a noção de ornatus, à feição dos antigos, seja considerado sob a noção de desvio, à feição moderna, esse estilo passaria menos pelos procedimentos formais de sua escrita que pelo movimento do pensamento por ela ensejado. Pois, para além da engenhosa sintaxe de seus versos, de seus incontáveis ritmos e da diversidade de seu vocabulário, é essa capacidade de despertar o pensamento, de se afirmar como poesia-pensante, uma quase-filosofia, que realmente a difere das demais poéticas nacionais que lhe foram contemporâneas. ${ }^{16}$

Trata-se, sem dúvida, de um lirismo tocado pela "musa filosófica." ${ }^{17}$ Não se deve, contudo, abordá-la como uma poesia filosófica ou como filosofia da literatura. Em primeiro lugar, não se encontram em Drummond os traços de intelectualismo, nem o tom sentencioso e afirmativo de um gênero propriamente filosófico, tampouco um diálogo explicitado com a tradição da filosofia. Além disso, a despeito de sua potência reflexiva, sua poesia não decorre de um sujeito-do-cogito ou de um sujeito-do-logos cuja aspiração seria a de uma unidade racional, nem tampouco estabelece um feixe lógico e demonstrável de proposições e conceitos. Trata-se, ao contrário, de um pensamento cambaleante, no qual raciocinar é sempre insuficiente; um pensamento tecido, talvez, em rivalidade com a própria filosofia; um pensamento fragmentado e ambíguo tal como os próprios versos nos quais ele se formaliza.

Vale notar que a força do pensamento que irrompe com o poeta seria menos o resultado de uma capacidade propriamente intelectual, o atributo de uma inteligência privilegiada, que o ato de dobramento do sujeito ao se declinar na linguagem em busca de sua singularidade, no duro combate contra si e contra o mundo. É a experiência do vivido a condição do seu pensamento; o autobiográfico é o seu itinerário. Nesse sentido, tem-se um pensamento tecido com idéias vitais, ou seja, com idéias concernentes à vida daquele que as formula, concernentes à potência e à preservação dessa vida: "é toda minha vida que joguei”, como declara o poeta na consideração de seu poema. ${ }^{18}$

Com Drummond, a hipertrofia da dimensão subjetiva, já presente na tradição poética brasileira, adquire uma feição problemática, transmigrando de um corpus escrito para um corpus histórico e cultural. ${ }^{19}$ É com o complexo agenciamento moderno configurado

\footnotetext{
${ }^{15}$ ANDRADE. Poesia e prosa, p. 258-261: Cantiga de enganar.

${ }^{16}$ Não seria justamente a potência reflexiva desse ato, esse convite ao pensamento, a motivação de Merquior para afirmar que os poemas drummondianos, "musicalmente desajeitados", não foram feitos para serem cantados ou falados, mas sim para serem lidos? Não seria essa mesma potência que Silviano Santiago evoca ao distinguir o poeta mineiro, nas nossas letras, como "o melhor e mais multifacetado intérprete" do século 20, observando que o caminhar conflituoso desses cem anos "está indissociavelmente interligado ao desenvolvimento em ritmo de vaivém de sua poesia"?

${ }^{17}$ A expressão é de Merquior, Verso universo em Drummond.

${ }^{18}$ ANDRADE. Poesia e prosa, p. 115-116: Consideração do poema.

${ }^{19}$ Essa diferença seria confirmada em estudo comparado acerca do traço autobiográfico e subjetivo em Drummond e em alguns poetas anteriores como em Álvares de Azevedo e Augusto dos Anjos.
} 
em sua poesia que a escrituralização da subjetividade na cena da literatura nacional é deslocada, alcançando o estatuto de pensamento filosófico sobre o sujeito, abordado em sua contingência histórica. Em Drummond, a poesia confessional e autobiográfica já não mais decorre da maturação ou do reconhecimento de uma interioridade em sua experiência expansiva frente à realidade. Já não se trata de encontrar forma adequada de expressão para uma "alma" atormentada, em descompasso com o mundo, nem de se lhe revelar as contradições intrínsecas, mas sim de pensar tais tormentos e contradições no palco da modernidade nacional, atualizando-os, recriando-os esteticamente. ${ }^{20}$

Não foi justamente essa a grande virada efetuada pelo escritor na tradição poética brasileira? Não foi ele quem, ao mesmo tempo livre e amarrado às formações discursivas anteriores, fiel e rebelde ao passado, definiu as margens de um novo território para a poesia moderna do país? Não foi ele quem subverteu a tendência intimista e introspectiva da poética nacional, "o gosto pela confidência" - característica destacada por Candido ao tratar da formação de nossa literatura - dando-lhe, sob laboriosa busca estética, uma dimensão meta-subjetiva? Não foi sua obra que desviou a poesia brasileira e, sobretudo, a mineira, dos bastidores da confidência, conduzindo-a como atitude existencial até o palco público de reflexões?

Essa obra tecida com a própria vida não indicaria, pois, uma tentativa de fazer da vida algo mais que pessoal? Afinal, em meio à sacudida semântica e sintática efetuada pelo autor na ordem da escrita, o que se trama não é uma verdadeira revolução subjetiva do discurso poético? A emergência de uma nova subjetividade poética - moderna e localizada? Um novo modo de enunciação, uma nova lexis, isto é, um novo modo de articulação entre o sujeito poeta e o sujeito-do-poema?

A escavação ontológica drummondiana configura novas ordenadas e novas tarefas para a subjetividade poética nacional. Essa virada deve-se, sobretudo, ao fato de todo o subjetivismo tramado em sua escrita derivar justamente da oclusão da demanda subjetiva, isto é, da renúncia à evidência ou à presença de uma interioridade pura ou originária. Isto porque o pensamento instituído na inquirição do eu do poema parte em direção ao que se deseja saber e não ao que já se sabe, lança-se para fora do saber, para dizer nos termos de Foucault, lança-se para fora dos estratos referentes ao eu e/ou à sua identidade, os quais definem um saber-de-si.

Longe de o deixar exposto a um vazio existencial, esse movimento rumo ao desconhecido parece fornecer-lhe o único espaço onde sua existência pode ser de fato experimentada. Em Drummond, o ato de dizer eu estaria menos afeito ao desejo de significar que ao de mapear algo ainda por vir. O que se vê em seu gesto autobiográfico é o "espelho de projeto não vivido". ${ }^{21}$

É no esteio desse lugar vazio do "si" ou do "sou", lugar sem alento - e, por isso mesmo, lugar de reflexão - que o poeta pode fabular um pensamento e uma poesia do

\footnotetext{
${ }^{20}$ É importante lembrar que o debate acerca do ser, em seus diversos desdobramentos, caracteriza a história da filosofia no século 20. Em Heidegger, Derrida, Deleuze ou ainda na fenomenologia e no existencialismo, a tematização em torno da identidade do ser assume um caráter prioritário. Talvez se possa pensar que, à distância e tramada sob o discurso poético, a obra drummondiana esteja inserida nesse conjunto de reflexões.
}

${ }^{21}$ ANDRADE. Poesia e prosa, p. 410-1412: "Elegia". 
eu, através dos quais pode falar de si, mas sem entoar um canto meramente particular. Esse desprendimento de si é a forma mesma de o poeta se colocar em cena. É a forma de ele se deixar imprimir, de deixar a paixão de um traço singular, de uma assinatura intangível imprimirem-se, de imprimir no corpo da letra, pública por definição, um eu cuja presença, como bem notou João Cabral, parece sempre au-delá de soi. ${ }^{22}$

\section{III}

Minha matéria é o nada.

Carlos Drummond de Andrade

Em Drummond, a memória, espaço privilegiado da pesquisa autobiográfica, apresenta-se também como caminho do pensamento e da procura de si. Porém, mesmo os textos abertamente autobiográficos, nos quais o empreendimento de recordação remete o poeta a seu passado familiar, a seu deserto itabirano, não resultam na descoberta de uma identidade, baseada na representação de uma origem ou de uma tradição inerentes ao sujeito. $\mathrm{O}$ que se figura no discurso memorialista drummondiano não é simplesmente um mecanismo de reminiscências inspirado nas semelhanças e contiguidades entre as sensações e os objetos do passado e os do presente. Seu eixo de relação com o tempo não é aquele que liga a verdade da enunciação à autenticidade vivida do representado. Por isso, a reelaboração do passado, embora acione os mecanismos de busca de si mesmo, não se pauta pela construção de uma identidade fundada na esteira das heranças e das filiações. Ao contrário, o movimento da memória inviabiliza o acesso a uma identidade original, por um lado, e recusa a idéia de uma tradição (familiar ou cultural) recebida passivamente, por outro, como registra "Os bens e os sangue": ${ }^{23}$

Às duas horas da tarde deste nove de agosto de 1847

Nesta fazenda do tanque e em dez outras casas de rei, q não de valete

Em Itabira Ferros Guanhães Cocais Joanésia Capão

Diante do estrume em q trança na palma dos coqueiros

Fiéis servidores de nossa paisagem e de nossos fins primeiros,

\footnotetext{
${ }^{22}$ Ver Correspondência de Cabral com Bandeira e Drummond.

${ }^{23} \mathrm{O}$ poema "Os bens e o sangue" aparece publicado pela primeira vez na Revista Anhembi, de São Paulo, no dia 2 de fevereiro de 1951, precedido da seguinte nota: "Embora persuadido de que não cabe explicação para um poema, além da que ele mesmo traz consigo, o autor julga conveniente informar quanto à gênese desta composição. Resultou ela da leitura de um maço de documentos de compra e venda de datas de ouro no nordeste de Minas Gerais, operações essas realizadas em meados do século XIX. Simultaneamente, certo número de proprietários, integrantes da mesma família, resolveu dispor de tais bens, havidos por meio de herança ou casamento. Até então, permaneciam sob domínio do mesmo grupo familiar os terrenos auríferos descobertos em 1781, na serra de Itabira, pelo capitão João Francisco de Andrade, que os transmitiu a seu sobrinho e sócio, o major Laje. Diz Eschwege que as lavras de João Francisco, em 1824, produziam mais de 3 mil oitavas de ouro. A exploração declinou com o tempo e por volta de 1850 vemos os donos se desfazem de jazidas e benfeitorias. Não se procure o significado de Lajos e andridos, palavras existentes no contexto, e que são meras variações de nomes de família da região. O nome Belisa, dado a animais, consta de inventário da época." Fazendeiro do ar $\mathbb{E}$ poesia até agora. RJ, José Oympio, 1955, p. 550.
} 
deliberamos vender, como de fato vendemos, cedendo posse, jus e domínio e abrangendo desde os engenhos de secar areia até o ouro mais fino, nossas lavras mto. Nossas por heranças de nossos pais e sogros bem-amados $q$ dormem a paz de Deus entre santas e santos martirizados.

Por isso neste papel azul Bath escrevo com a nossa melhor letra estes nomes $q$ em qualquer tempo desafiarão tramóia trapaça e treta

Teatro fantástico dividido em oito atos-estrofes, linearmente desconjuntados e enunciados por vozes diferentes, dialógicas, o texto instaura um tempo absurdo, ancestral e profético, futuro do passado, no qual o poeta retorna a seus parentes remotos, a longínquos documentos escriturais de família, a fim de deslocar o jogo das heranças e legados que pesará sobre seu próprio destino. Toda uma história pessoal e familiar é, assim, reconstruída e transformada no traço poético, de forma a criar uma justificativa para a cisão provocada pelo filho-escritor na tradição dos patriarcas-fazendeiros:

De nossa mente lavamos o ouro como de nossa alma um dia os erros se lavarão na pia da penitência. E filhos netos bisnetos tataranetos despojados dos bens mais sólidos e rutilantes portanto os mais completos irão tomando a pouco e pouco desapego de toda fortuna e concentrando seu fervor numa riqueza só, abstrata e una.

Desse modo, ao imprimir uma torção em seu romance familiar, revirando seu nexo de causalidades, o poeta rasura a escritura testamental, borra o papel Bath, como se aceitasse o desafio lançado no documento referido no poema. Na trapaça de sua escrita, o sujeito em cena aparece deserdado desde às suas origens, aparece desde sempre reduzido à "condição ninguém" e marcado a negar os seus:

$$
\begin{aligned}
& \text { Este figura em nosso } \\
& \text { pensamento secreto. } \\
& \text { Num magoado alvoroço } \\
& \text { o queremos marcado } \\
& \text { a nos negar; depois } \\
& \text { de sua negação } \\
& \text { nos buscará. Em tudo } \\
& \text { será pelo contrário } \\
& \text { seu fado extra-ordinário. } \\
& \text { Vergonha da família } \\
& \text { que de nobre se humilha } \\
& \text { na sua malincônica } \\
& \text { tristura meio cômica, } \\
& \text { dulciamara nux-vômica. }
\end{aligned}
$$

Destituído do patrimônio familiar, de seus bens de direito e de sangue, expulso das minas e das terras, ele poderá, então, trilhar seu rumo próprio, em busca de uma "riqueza abstrata e una", mas agora sob a contemplação aquiescente de seu clã, como se esse fosse seu "fim natural": 
Ó poeta de uma poesia que se furta e se expande

à maneira de um lago de pez e resíduos letais...

és nosso fim natural e somos teu adubo,

tua explicação e tua mais singela virtude...

pois carecia que um de nós nos recusasse

para melhor servir-nos.

O gesto engendrado pelo poema é, por definição, desconstrutor, posto que o passado, deliberadamente rasurado e deslocado pelo poeta, não é mais fonte de um sentido original e verdadeiro. A "viagem na família", ao ser transfigurada no traço da escrita, não o conduz a um tempo perdido, tempo-do-início no qual estariam os segredos do ser ou da existência, mas a um tempo-tramóia, cujo estatuto é ficcional, haja vista que a própria origem é transformada em terreno de fabulação. O movimento do texto revela que o sentido procurado não se situa no princípio ou na origem, ao contrário, deve ser elaborado ou restaurado através de novas maquinações, para formular com Deleuze.

Portanto, não se trata de buscar a condição apaziguadora das raízes, do começo, nem a conservação dos conteúdos memoráveis do passado e da família, a um só tempo autoritários e protetores. $\mathrm{O}$ que se tem é um passado reencenado, através do qual o sujeito-do-poema descola-se da tradição recebida, refundando, sob a vigília dos urubus no telhado, sua própria genealogia:

Os parentes que eu tenho não circulam em mim.

Meu sangue é dos que negociaram, minha alma é dos pretos,

minha carne, dos palhaços, minha fome, das nuvens,

e não tenho outro amor a não ser o dos doidos.

Com a inversão realizada, o poeta pode expiar culpas, acertar dívidas, conjurar os mortos, livrar-se em parte da responsabilidade para com os antigos, a fim de não ser devorado por seu passado voraz, ainda que a absolvição seja apenas aparente, simulada e, portanto, transitória. A travessia realizada historicamente no transcurso das gerações, sob tumultuoso conflito pessoal, figura amortecida no poema, como se fosse fruto do destino, como se o vir-a-ser-escritor já estivesse previsto desde sempre no passado imemorial e azul da família. Esse modo de desterritorialização do passado abala todo e qualquer fundamento originário, criando as condições para o poeta renunciar ao dever da representação, também no âmbito da memória. Não há uma identidade pré-concebida a ser representada no espaço das heranças e das tradições familiares. Em Drummond, a memória é também o lugar do desencontro e do desentendimento. Do novo testamento não resta ao sujeito posto em ato senão sua "parte de nonada", vazio a ser reinventado:

Mais que todo deserdamos

deste nosso oblíquo modo

um menino inda não nado

(e melhor não fora nado)

que de nada lhe daremos 
sua parte de nonada

e que nada, porém nada

o há de ter desenganado. ${ }^{24}$

A lei das origens, a "ciência do sangue" é submetida à ficcionalidade da escrita e, a esse título, é lançada à deriva das retomadas, à lógica do recomeço, à repetição indefinida do instante inaugural - vazio repetidamente entrevisto. Em sua arqueologia de si e do passado, em seu aprendizado ontológico, o poeta descobre, como se diz em epígrafe, que sua matéria é o nada, pois o retorno à origem, ao invés de lhe conduzir para os seguros laços fundadores, lança-o no abismo do "nonada". ${ }^{25}$ É justamente a partir desse signo vazio ou esvaziado que ele pode pensar sua identidade, ou melhor, livrar-se dessa "identidade do sangue que age como cadeia", para valer-me de um verso de "Como um presente". ${ }^{26}$ É a ausência imposta pelo signo que, ao desestabillizar a analítica existencial, tece o discurso identitário sobre as ruínas da tradição familiar; des-identifica todo o conceito do um, afastando-lhe de uma verdade reveladora. No espaço-tempo do nonada, "seu nome familiar é um chiar de ratos sem paiol." 27

Essa viagem ao vazio da origem apresenta-se também no "deserto de Itabira" onde o poeta reencontra o pai, em teatro igualmente fantasmático:
No deserto de Itabira
a sombra de meu pai
tomou-me pela mão.
Tanto tempo perdido.
Porém nada dizia.
Não era dia nem noite.
Suspiro? Vôo de pássaro?
Porém nada dizia.

Juntos, como em um sonho, pai e filho percorrem os lugares do passado, nos quais "as coisas voltam a existir, / irrespiráveis e súbitas". A cena elabora-se a partir do desejo de reconciliação do filho, que deseja acertar as contas, pedir e receber perdão, dizer e ouvir o que, em vida, não foi pronunciado, mas o pai mantém-se em "distintos silêncios":
Que cruel, obscuro instinto
movia sua mão pálida
sutilmente nos empurrando
pelo tempo e pelos lugares defendidos?
Olhei-o nos olhos brancos.

\footnotetext{
${ }^{24}$ ANDRADE. Poesia e prosa, p. 229-233. O poema não foi apresentado aqui em sua seqüência correta. ${ }^{25}$ É interessante notar que Grande sertão: veredas, de Guimarães Rosa, publicado poucos anos após Claro enigma, inicia-se justamente com a expressão grifada no poema de Drummond: nonada. O romance de Rosa, o qual pode ser lido sob o viés da genealogia identitária colocada em marcha pelo narrador, valese do signo drummondiano da memória.

${ }^{26}$ ANDRADE. Poesia e prosa, p. 186.

${ }^{27}$ ANDRADE. Poesia e prosa, p. 442.
} 


\section{Gritei-lhe: Fala! Minha voz vibrou no ar um momento, bateu nas pedras. A sombra prosseguia devagar aquela viagem patética através do reino perdido. Porém nada dizia.}

O poeta-filho desespera-se: "Fala fala fala fala", mas o outro segue calado. Ele tenta, em vão, puxar o pai pelo casaco, que imediatamente "se desfazia em barro". Por sobre o silêncio do pai misturavam-se os silêncios de outros antepassados, emergiam outras faltas e separações.

"Porém nada dizia" - o verso repete-se ao longo das onze estrofes do poema. De imediato, tal verso revela o insistente e intrigante silêncio do pai. No entanto, sua repetição abre também a possibilidade de outra leitura, ainda derivada da primeira: o pai dizia o nada, ele não tinha nada a dizer em relação ao desejo do filho, então, dizia o nada. Sua resposta era o nada. O reencontro imaginado pelo filho permanece sob o emblema de um vazio, o silêncio da origem. Mas, revirando o verso, pode-se ler também que é o nada que dizia: "nada dizia". Como se o nada dissesse, como se o nada fosse o sujeito da enunciação, isto é, do silêncio. É a voz do nada que se escuta no texto da memória drummondiana. É justamente aquilo que não pode se alcançar que se pronuncia no silêncio do pai, sob a sombra do pai, no deserto de Itabira.

No "país da remembranças" de Drummond, ${ }^{28}$ não mais se trata da memória do acontecimento, mas da memória transformada em acontecimento. Pois, em sua forma de invocação do tempo, o passado ressurge de forma absolutamente nova: não como esteve supostamente presente um dia, não é mais relativo ao presente em relação ao qual é agora passado, mas referido ao presente da escrita, ao movimento de subjetivação colocado em curso sob o signo da ausência. Como pontua Foucault, "a pesquisa da proveniência não funda, muito pelo contrário: ela agita o que se percebia imóvel, ela fragmenta o que se pensava unido; ela mostra a heterogeneidade do que se imaginava em conformidade consigo mesmo". ${ }^{29}$

O tempo já não se reporta, assim, ao período que ele mede. Há nesse mecanismo drummondiano de rememoração uma certa dimensão performativa, na medida em que a tradição e, em última instância, o próprio passado são colocados em movimento, submetidos às permanentes reinscrições, de acordo com as contingências do presente-da-escrita. Nesse sentido, vale ressaltar que diversos textos memorialísticos do poeta como, por exemplo, "A mesa", "Viagem na família", "Documentário", "Morte de Neco Andrade" e "Comunhão" guardam um certo ar teatral ou cinematográfico. Lembram um teatro ou um cinema de tradução da memória, como se se tratasse de um permanente pós-escrito de si mesmo, no qual o sujeito do texto "está filmando seu depois", revendo, no vazio da cena arqueológica, aquele que "já não é ele; é um mais tarde, sem direito de usar a semelhança". ${ }^{30}$

\footnotetext{
${ }^{28}$ ANDRADE. Poesia e prosa, p. 277-279: Morte das casas de Ouro Preto.

${ }^{29}$ FOUCAULT. A arqueologia do saber, p. 21.

${ }^{30}$ ANDRADE. Poesia e prosa, p. 442: Documentário.
} 
Nessa vertente autobiográfica de pós-escritos fomentada pela poética drummondiana, com suas reacomodações e sobrecodificações do tempo, pontua-se um outro modo de arquivar o passado e a si próprio, fora das formas de representação que induzem à identidade, ao idêntico, ao estável, ao eterno ou ao mesmo. Dessemelhante absoluto, o sujeito da escrita afasta-se de qualquer fundamento ou significação originária em relação à identidade, retirando o caráter positivo do conceito. Seu percurso no passado não procura revelar a proveniência genealógica, mas dar voz ao que se passou na dispersão, indicar seus acidentes e suas falhas. Em Drummond, a memória não é uma categoria da semelhança, pois que ela revela são diferenças. Com ela, o poeta faz ver que nem tudo que reluz é ouro, faz ver que os áureos tempos são de cobre, que os áureos tempos dormem no chão. ${ }^{31}$

Sob o dispositivo de sua "memória fosca", diferida, o poeta engendra uma máquina discursiva e autobiográfica de permanente auto-reconstrução, com a qual pode atravessar as franjas do moderno e traçar para si um modo de existência singular. Com ela, sua genealogia do ser, como se lê em "Descoberta", não encontra senão

a polpa deliciosíssima do nada. ${ }^{32}$

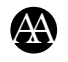

\section{A B STRACT}

This paper examines the "incessant search for identity" and the "autobiographical obsession" in the poetry of Carlos Drummond de Andrade.

\section{KEYWORDS}

Carlos Drummond de Andrade. Brazilian poetry. Memory.

\section{REFERÊNCIAS}

ANDRADE, Carlos Drummond de. Poesia e Prosa. Rio de Janeiro: Nova Aguilar, 1992. ANDRADE, Carlos Drummond de. Fazendeiro do ar $\mathcal{E}$ poesia até agora. Rio de Janeiro: José Oympio, 1955.

ANDRADE, Carlos Drummond de; ANDRADE, Mário de. Carlos e Mário: correspondência completa entre Carlos Drummond de Andrade e Mário de Andrade. Rio de Janeiro: Bem-Te-Vi, 2002.

ARRIGUCCI JÚNIOR, Davi. Coração partido. São Paulo: Cosac \& Naify, 2002.

BARTHES, Roland. Roland Barthes por Roland Barhes. São Paulo: Estação Liberdade, 2003.

CORREIA, Marlene de Castro. Drummond: a magia lúcida. Rio de Janeiro: Jorge Zahar,

\footnotetext{
${ }^{31}$ ANDRADE. Poesia e prosa, p. 136-138: Nos áureos tempos.

${ }^{32}$ ANDRADE. Poesia e prosa, p. 345: Descoberta.
} 
2002. $192 \mathrm{p}$.

DELEUZE, Gilles; GUATTARI, Félix. O que é a filosofia? São Paulo: Editora 34, 1992. DELEUZE, Gilles. Conversações. São Paulo: Ed. 34, 1998.

FOUCAULT, Michel. A arqueologia do saber. Rio de Janeiro: Forense Universitária, 1997.

MELO NETO, João Cabral de. Correspondência de Cabral com Bandeira e Drummond. Organização, apresentação e notas Flora Süssekind. Rio de Janeiro: Nova Fronteira, Fundação Casa de Rui Barbosa, 2001.

MERQUIOR, José Guilherme. Verso universo em Drummond. Rio de Janeiro, José Olympio, 1975.

MIRANDA, Wander Melo. Corpos escritos: Graciliano Ramos e Silviano Santiago. São Paulo, Belo Horizonte: Ed. USP, Ed. UFMG, 1992.

SANTIAGO Silviano. Carlos Drummond de Andrade. (Poetas modernos do Brasil). Petrópolis: Vozes, 1976. 